\title{
Social Influence And Savings Behavior: Evidence From A Developing Country Context
}

\author{
Eva Mpaata ${ }^{*}$, Naomy Koskei², Ernest Saina ${ }^{3}$ \\ 1,2,3 Moi University, Kenya \\ *Corresponding author: evahmpaata56@gmail.com
}

Article History

Received 2020-06-14

Revised 2020-07-16

Accepted 2020-07-16

Published 2020-07-24

\section{Keywords \\ Savings Behavior \\ Social Influence \\ Financial Literacy \\ Developing country \\ Self-control}

\section{How to cite?}

Mpaata, E., Koskei, N., \& Saina, E. (2020). Social Influence And Savings

Behavior: Evidence From A Developing

Country Context. SEISENSE Journal of

Management, 3(4), 56-67. doi:

$10.33215 /$ sjom.v3i4.396

\section{Abstract}

Purpose: This paper highlights the relevance of Savings Behavior and the impact of Social Influence on Savings Behavior in a developing country utilizing both life cycle and economic theories

Methodology: This paper presents findings from a thorough review of the literature. Relevant articles were reviewed on both savings behavior and social influence. The articles consisted of both contexts developed versus developing.

Findings: The findings suggest that from the developed country context, Social Influence positively affects Savings Behavior, which is not the case for the developing economies that show the negative impact of social influence on savings behavior. Therefore, financial education and literacy training are two of the means of encouraging individual self-control in these developing economies despite their vulnerability to social influence to encourage positive savings behavior.

Implications: Individuals are encouraged to save, especially during their productive ages, along with their lifespan. This can be done by obligatory deductions for those that are officially employed.

Originality/Value: This paper reveals a bibliography theoretical review on Social Influence and Savings Behavior within the developing country context. The paper presents the puzzle about the effect of Social Influence and Savings Behavior in the emerging economy. The majority of savings behavior research undertaken in the developed economies shows the positive effect of social influence on savings behavior, which is not the case in the developing economies. 


\section{Introduction}

Savings behavior is a critical requirement for individuals to help them find out how to solve potential future financial decisions on their own by learning and rehearsing sound financial abilities in their lives. Saving instills control among the individuals from the consumptive manner and learning on how to spend wisely (Ariffin, Sulong, \& Abdullah, 2017). To demonstrate an appropriate savings behavior does not "come overnight" but can be attained through the social influence of family, friends, and colleagues by way of nurturing, mentoring, and sharing of information concerning money management practices. However, putting money aside for the future is a complex decision that warrants a good savings behavior (Gerhard, Gladstone, \& Hoffmann, 2018).

This research adopts the principle of Gerhard et al. (2018) that savings behavior is a mixture of future needs expectations, saving action that leads to better wellbeing and wealth creation. Savings are, therefore, vehicles destined for economic growth, whose future drivers are individuals making their savings behavior principal in any economy (Khatun, 2018). This research reviewed articles that are unusual in studies in the developing world linked to social influence and behavior.

According to (World Bank., 2017), the global saving rates percentage of Gross Domestic Product (GDP) are as follows; East Asia \& Pacific at 45\%, South Asia 32\%, North Africa at 23\%, Europe \&Central Asia at 23\%, Canada at 19\%, the United States at 18\%, Latin America at 17\%and Sub Saharan Africa at 14\%. Saving rates have steadily increased in East Asia, have stagnated in Latin America and have been volatile in Sub-Saharan Africa, North Africa, and have deteriorated in South Africa, and have steadily increased in West Africa (Kudaisi, 2013). Furthermore, the World Bank. (2017)States that developing countries saving rates are low, which in turn affects their level of investment. The world has experienced a marked difference in saving rates over the last three decades, and this has been particularly dramatic in African countries. According to Deaton (2005) and the World Bank. (2017) Africa generally has the lowest saving rates with a constant decline over the past three decades, and this has negatively impacted the economies with slow growth. Africa is seen to perpetually have low saving rates (Elias \& Worku, 2015).

According to the 2011 Global Findex survey, for example, a quarter of the most deficient $40 \%$ of households in Sub-Saharan Africa do not have bank accounts (Demirguc-Kunt, Klapper, Singer, \& Van Oudheusden, 2015). Approximately 44 percent of teenagers between the ages of 17 and 25 and 11 percent between the ages of 40 and 55 are victims of consumptive behavior (Herawati, Candiasa, Yadnyana, \& Suharsono, 2018).

Most research focused primarily on the direct effect of social influence on savings behavior in developed countries and mostly found significant effects (Dangol \& Maharjan, 2018; Erskine, Kier, Leung, \& Sproule, 2006; Jamal, Ramlan, Karim, \& Osman, 2015). Many of these studies were done in the developed world, excluding the developing context, which is addressed by this research. Further still, there has been limited research in the area of savings behavior at the micro-level, particularly for an individual (Supanantaroek, Lensink, \& Hansen, 2017; Tharanika \& Andrew, 2017). This study attempts to close the limited research in the area of savings behavior at the micro-level, particularly for an individual more so in the developing country context (Supanantaroek et al., 2017; Tharanika \& Andrew, 2017). The majority of the research has focused on saving behavior at the macro level, an example being a study by (Kaberuka \& Namubiru, 2014) on the effect of remittances on gross domestic savings in Uganda. However, studies regarding Saving Behavior at the microlevel is limited in the Sub-Saharan African countries (Asare, Segarra, Gertrude, \& Asiseh, 2018). An example of such a study was on the determinants of household savings among low-income individuals in rural Uganda, whose primary focus was on households' saving behaviors by Chowa, Masa, and Sherraden (2012). The saving behavior of an individual is justified as part of the social environment of any society. It is supposed to be successful, thus boosting the growth and development of the economy. To achieve the right saving action, it is important to look at the social context in which the individual resides. 
This article, therefore, has two specific objectives;

1. To examine the relevance of Savings Behavior in developing countries

2. To establish the impact of Social Influence on Savings Behavior in developing countries

In the subsequent section, we track each specific objective to enhance acceptable individual savings behavior. The purpose of the study is to demonstrate the relevance of saving behavior in the developing country context. This paper reviews literature to accomplish the mentioned objectives. The article is structured as follows; in the following section, we examine the theoretical framework, then a debate on the relevance of savings behavior, followed by a discussion on the effect of social influence on savings behavior, applied methodology, findings, and discussions. The article concludes with findings, recommendations, theoretical and practical implications, and, lastly, future research areas.

\section{Literature Review}

\section{Theoretical Underpinning Of Savings Behavior}

Savings Behavior can be seen at both the household and national levels. The saving activity at the household level is mainly for consumption or retirement purposes. The household savings behavior is explained by the Lifecycle Hypothesis, while the national saving is explained by the economic theory. These theories are examined in the following section

\section{Lifecycle Hypothesis ( $\mathrm{LCH})$}

The lifecycle hypothesis (LCH) by Modigliani and Brumberg (1954) and later in Ando and Modigliani (1963) proposes that households seek to optimize utility derived from their lifetime resources by allocating them optimally between current and future consumption. Lifecycle theory suggests that the primary motivation for investing is to accumulate money for later consumption and, in particular, for retirement. In its simple wording, the lifecycle theory suggests that savings behavior is forward-looking and driven by a desire to plan for future spending above future incomes during life. The lifecycle hypothesis posits that the primary motivation for saving is to accumulate resources for later expenditure and, in particular, during retirement. In its basic formulation, the lifecycle hypothesis posits that savings behavior is forward-looking and driven by the desire to prepare for future expenditures above later income throughout life (Jappelli \& Modigliani, 1998). Several saving motives were listed by Keynes (1936). Most of these motives have now been incorporated into the lifecycle model (Modigliani \& Brumberg, 1954). In this model, saving depends entirely on current income, with households saving only a portion of that income. Early versions of this model explain the old-age provision motive as the main saving motive: individuals save while working to counteract the income drop at retirement. The basic version of the lifecycle model has been extended to include also other saving motives, most prominently the precautionary savings motive. Precautionary saving can explain a large share of individual and aggregate wealth accumulation (Gourinchas \& Parker, 2002).

The Lifecycle Hypothesis ( $\mathrm{LCH}$ ) also indicates that households seek to maximize the use of their lifetime resources by making optimal use of them between current and future use. In the Keynesian model, saving depends entirely on current income, with households saving only a portion of that income. Modigliani (1970) demonstrates how the saving ratio of households is independent of income. Instead, it depends on the rate of long-term income growth. However, the validity of the LCH hypothesis for developing countries has been questioned. The model of savings behavior may not extend to low-income countries, because low-income people may not be able to save enough while young and active to support old-age consumption as the model suggests. 


\section{Economic Theory}

Early theories of economic growth have shown the importance of savings as a source of capital accumulation and, therefore, of growth. Economic theory has long argued that saving or capital accumulation is the primary determinant of economic growth that can be interpreted as a sustainable long-term rise in the country's income (Geda \& Shimeless, 2006). The high rate of capital accumulation, funded by high domestic savings rates, is at the core of many classic models of economic growth.

Domestic savings are, therefore, an important indicator and a prerequisite for higher levels of growth. Solow's standard growth model, which underlines the importance of savings in economic growth, indicates that higher savings rates precede a temporary increase in inflation as the country moves toward a higher level of growth. In this and many other classic growth models, higher savings are expected to turn into faster capital stock growth, thereby increasing economic growth (Bonga-Bonga \& Guma, 2017).

\section{The Relevance Of Savings Behavior To Households}

Household savings have drawn considerable interest in the literature on economics, with a particular focus on the different reasons for saving conduct that is possibly complex and interrelated. Browning and Lusardi (1996) provide a comprehensive review of household savings from both an empirical and a theoretical viewpoint, in which they address savings motives based on those described by Keynes (1936). Such motivations include precautionary saving where households keep a contingency fund in the event of future adverse events; smoothing income and expenditure over the life cycle; and inter-temporal replacement motivation for which households benefit from accumulating savings interest (Brown \& Taylor, 2016).

Saving is a delayed investment; savings have always been studied concerning the smoothing actions of consumption. This is because the decision of households or individuals to consume or save is a joint family decision. In case households save too little, they might face financial difficulties in addition to having deficient emergency savings, which, in turn, will increase anxiety and leads to serious health problems (Prawitz et al., 2006). From a broader perspective, there will be insufficient funds available for the government to invest in social and physical infrastructure. It has been further argued that (micro) savings products are probably one of the best financial instruments to reduce poverty.

Savings are vital because, unlike income, saving helps individuals to accumulate and hold on to wealth over time. Typically, people's savings behavior relies on their present income and their present level of consumption (Awais, Laber, Rasheed, \& Khursheed, 2016). There is also growing evidence that poor people are, in principle, able and willing to save. However, for several reasons, among which is a lack of financial knowledge, lack of self-control savings remains limited. To improve savings behavior, there is a strong need to encourage a better savings culture. According to many people, it is crucial to improve the savings culture of people and thus to develop savings attitudes at a young age (De Noose, 2011).

At an individual level, savings smoothen the individual's consumption patterns, thereby improving on their welfare among others as well as enhancing the economic growth of a nation, through the provision of the lump sum for investment at the macro-level (Supanantaroek et al., 2017).

\section{National Benefits Of Savings Behavior}

Most conventional growth models indicate that higher savings rates lead to higher growth by growing the pool of domestic capital available (Romer, 1986; Solow, 1956). It promotes a faster accumulation of physical capital, which is known to be the driving force of economic growth. Over the past decades, saving has played an essential role in the process of economic growth and development. Logically, saving stimulates investment that causes a single country's economic growth. Domestic savings are, therefore, an important indicator and precondition for higher levels of growth. The speed of economic growth is determined by the ability to save 
because a high savings rate will drive up the rate of investment and consequently stimulate economic growth (Turan \& Gjergji, 2014).

A growing literature emphasizes the crucial role of savings in the process of economic growth in addition to them providing lump sums for investments that enable households to build up a financial safety net and hence may serve as an insurance mechanism (Dupas \& Robinson, 2013). Also, the domestic savings of a nation ensure that the vulnerability of a country's dependence on foreign capital is reduced (Njenga, Onuonga, \& Sichei, 2018).

Savings play an important role at different levels of the economy where households, companies, and government, when carefully interlinked, jointly contribute to the economic growth of the country. This aggregated saving decision is the primary determinant of national saving (Geda, 2006). Funds that are placed in financial assets are channeled through financial intermediaries for investments, and subsequently, enriching the country through higher productivity and economic growth. It is argued that the speed of long-run economic growth depends on the ability to save since a high savings rate will increase investments, affect the capital accumulation and consequently stimulate economic growth (Joshi, Pradhan, \& Bist, 2019).

High savings leads to accumulation of wealth that allows individuals to improve their living standard and could hedge the country against economic downturns and financial crisis, insuring against the time of economic shocks and an essential way of improving wellbeing (Mahdzan \& Tabiani, 2013). In some countries, savings are considered as the backbone to specific sectors of its economy. In other nations, for instance, household savings is regarded as the most critical investment resource for the development of the non-oil sector, while its foreign capital is contributing more to the production of natural resources like oil and gas.

To summarize, individual savings will not merely benefit households but benefit the entire nation, as well. Therefore, it is essential to know factors influencing individuals' savings behavior as it is essential in maintaining economic growth since it will give benefits to the entities involved, such as households, financial institutions, government, and other related stakeholders. Hence savings play an essential role in both a nation and individual financial wellbeing (Findley \& Caliendo, 2015; Gerhard et al., 2018; Otto, 2013).

\section{The Impact Of Social Influence On Savings Behavior}

Social Influence has both positive and negative effects on human behavior. This is based on the fact that Social Influence allows both a group and an individual to achieve a mutual or individual goal. Nevertheless, the Social Influence may instead make sub-optimal decisions for individuals (Kast, Meier, \& Pomeranz, 2018). The previous studies undertaken indicate that Social Influence is active at increasing savings among individuals (Homan, 2016). This is achieved through strategies that include: setting goals, regular follow-up to meetings, peer pressure from others, monitoring the success of others, symbolic incentives for those who perform well, and guidance on how to accomplish one's goal. SI entails the influence of others' behaviors, depending on the social environment around them. Social influence involves the exercise of social power by a person or group to change the attitude or behavior of other persons or groups in a particular direction (Franzoi, 2006). Mangleburg, Doney, and Bristol's (2004) study, as quoted in Zaihan (2016), views social influence as the degree to which family, friends, and colleagues affect the state of mind, thinking and conduct of the person.

Hira (1997) indicated that the most important sources of influence on the financial attitudes and beliefs of respondents were identified among the various socialization agents, family in general, mothers, and fathers in particular. According to Firmansyah (2014), children inherit the attitude and behavior of their parents, and this can predict the type of financial decisions and management that they will make in the future. Money values are passed down from parents to children through direct and indirect messages. Besides, Lyons (2007) found that about 68 percent of individuals reported receiving financial information from their parents. Bowen (2002) also 
found that there is a significant link between adolescents' and parents' understanding of money. Social influence involves the exercise of social power by a person or group to change the attitude or behavior of other persons or groups in a particular direction (Franzoi, 2006). Several kinds of literature acknowledged the role of parents as the key to their children's financial socialization, in which parents are highly influential in developing their children's financial behavior. Thus they should become role models to their children in managing their financial affairs (Sam, Geetha, \& Mohidin, 2012). Webley and Nyhus (2006) further added that economic socialization (namely discussing financial matters with parents) would have an impact on children's future orientation

Children who have a good relationship with their family are more likely to be future-oriented and have good financial behavior. Shim, Barber, Card, Xiao, and Serido (2010), discovered that the role played by parents is significantly greater than the role played by working experience and high school financial education of young adults. A set of supportive social support from parents and family members are crucial in helping young adults and adolescence achieve their successful adult life. When parents displayed positive financial behavior, they will become financial role models to their children and will trigger positive attitudes and behavior amongst young adults. Savings' decisions are complex, requiring individuals to have substantial economic knowledge and information. This may, therefore, be the case that parents with a certain degree of financial literacy may try to impart these skills to their offspring to equip them with financial management skills for the future. As a result, children and young adults may develop financial attitudes from their parents. Saving decisions during childhood will affect attitudes towards finances at the later stages of the life cycle and therefore have consequences for saving actions experienced during adulthood (Brown \& Taylor, 2016).

Norvilitis and MacLean (2010) revealed that parents who provide a hands-on approach to teaching their children about money management, allowances, and bank accounts motivate them to lower their credit card usage in college. The researchers further added that childhood is the most crucial period that will influence an individual's behavior and attitude during adulthood. Therefore, parents play an essential role in influencing children in managing their financial affairs. Besides parenting factors, peer influence could also predict individuals' financial behavior. Duflo and Saez (2002) found out that people with similar preferences tend to belong to the same group, thus creating a correlation between the group and individual behavior.

Bucciol and Veronesi (2014) suggested that parental teaching is more effective than receiving formal education at school, and based on different socio-demographic variables, they show different behavior. The parental teaching method determines the ability to meet financial issues in the future, and it is more effective, especially when different teaching methods are combined. The most effective strategy is teaching to save during childhood and adolescence.

Similarly, a study by Jamal et al. (2015) showed that the impact of colleagues has a critical role in choosing the saving capacity of a person. Zaihan (2016) found that even though the parents or guardians have formed positive financial behavior in their children, peer socialization angle still exists in an individual's savings behavior since savings behavior of individuals could be influenced by the association in spending exercises during the social time and exchanging ideas about financial management matters among their peers. (Jamal et al., 2015)Stated that peer influence could also affect the financial behavior of individuals. Alwi, Amir Hashim, and Ali (2015) indicated that when making choices, people are affected by peer pressure. Moreover, Laible, Carlo, and Roesch (2004) stated that an individual's behavior is acquired from direct and indirect interaction with their friends. 
Dangol and Maharjan (2018) opined that both peer and parent remain as potent socialization agents that determine the behavior of adolescence in the future. Their needs were often derived from desires than financial needs. From childhood, they imitated what their parents do. People who discuss financial problems with parents had better skills to fulfill their financial needs. Young people also learned from direct and indirect interaction with peers; through discussions, rulemaking, reinforcement, and modeling.

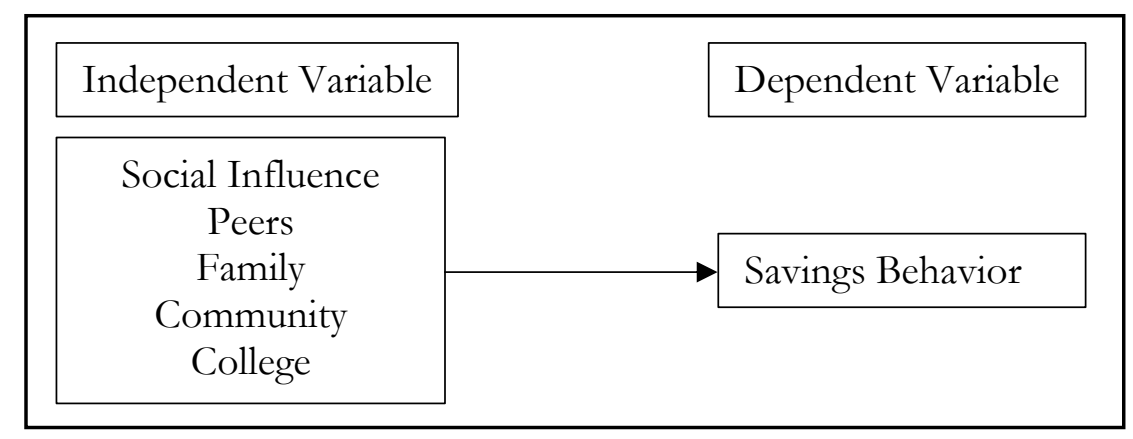

Figure 1 - Conceptual Framework

The philosophical model above suggests that Social Impact encompasses friends, families, society, and college. These affect the behavior to save a person. In the context of developing countries, people save in various forms, including cash, cattle, land, crops, and so on.

\section{Data and Methodology}

Only English-language papers in core journals were included in our sample. The literature reviewed included articles on both social influence and savings behavior within the period of 1996 to 2019. Given our search criteria outlined below, some 520 papers were reviewed. The primary sources of research include the Citation Index for Social Science, JSTOR, and Google Scholar. Many of these publications were published in a full-text format where it was feasible, or copies were requested through the inter-library system. The criteria for selecting the articles were based on the key search words of social influence and savings behavior.

Only relevant articles were used in the review and further analysis. The rationale behind the journal selection is on the assumption that savings behavior contributes to both the entrepreneurial and behavioral finance discipline that is a necessity in developing countries.

\section{Findings}

\section{Puzzle In The Developing Country Context: Social Influence And Savings Behavior}

A great deal of savings in the African context is seen through the impact of social capital, which is mainly evident among the unions, as information transmitted through these organizations increases the proportion of liquid assets held in the form of deposits that yield a return. However, the extent to which households can access financial products, in particular deposit products, is a vital issue for developing countries. For low-income households, there may be many barriers to savings in formal financial institutions other than access, including lack of knowledge or information that could lead to mistrust and uncertainty about available returns. In a general sense, the role of social networks in developing countries is well known. Most empirical literature identifies interpersonal relationships between members within villages or communities as an effective means of eliminating information failures, thereby encouraging saving (Newman et al.,2012).

In developing countries, limited access to formal financial institutions means that individuals and households rely mainly on informal networks to create savings. These informal saving strategies include saving livestock or 
jewelry, saving at home' under a mattress, saving with a neighbor or, in a more organized way, engaging in the Rotating Savings and Credit Associations (ROSCAs). Nonetheless, in developing countries that are vulnerable to unforeseen events such as health degradation, the death of a family member, overwhelms and scares the few savings that would have accrued, thereby hindering economic activity and growth (Ky, Rugemintwari, \& Sauviat, 2018).

The majority of people in Africa are not using Social Influence to save but rather to spend. This is more evident among college students who, with more experience and socialization, may develop poor habits and attitudes as a result of these influences, as well as gain some basic knowledge for better financial management, which could explain the mixed effects of these influences on savings and the consequent financial problems (Sabri \& MacDonald, 2010).

In most developing countries, the majority of the population is poor and can access funds through ROSCAs. Individuals involved in ROSCAs frequently configure the startup date by the date they are allocated to obtain the pot, as many ROSCAs use a predetermined order to distribute the savings pot. Since these saving strategies involve taking high risk, most individuals in ROSCAs are disbanded by obtaining their share of the pot, often without notice, thus preventing the savings culture (Ky et al., 2018). Likewise, in cases where individuals engage in ROSCAs, since there is a generally predetermined order, it is impossible to access the money immediately when an emergency arises. In such situations, some people turn to their relatives for support, thus deterring their saving actions. Worse still, if relatives do not have liquid funds, they turn to sell their properties (Collins, 2009).

Young people are the most significant proportion in Sub-Saharan Africa. Parents, peers, school staff, and financial institutions are offering support to this vulnerable group in promoting financial inclusion through savings that are an international priority. This can be achieved through savings promotion programs. Financial inclusion is vital for economic and social development and the reduction of poverty. Increasing evidence indicates that financial inclusion for young people, in particular engagement in savings programs, is associated with a wide range of positive outcomes in areas such as health, education, social-emotional development, and financial wellbeing.

Financial education in schools or financial institutions is essential for building trust and promoting savings. Nevertheless, in addition to limited funds and competing demand for money, this group of individuals is negatively influenced by peer influence, thereby discouraging saving. Also, school administrators fail to provide encouragement or guidance to youth, thereby missing the opportunity to save (Zou et al., 2015). Using mobile money, individuals can easily exchange cash for e-money or vice versa with mobile money agents across the world. Once the deposit has been made, they can either keep it safe on their mobile phone as savings or move the balance via SMS to any other mobile phone in the country or abroad. Mobile phones are seen as an opportunity to provide essential banking services to poor people who have fewer alternatives than rich people. However, the liquid savings option provided by mobile money, which can be accessed anywhere and at any time, could increase family assistance and could, therefore, harm individual savings. This is aggravated by the withdrawal tax feature of mobile money, which may help people withstand unnecessary spending on the one hand, but may discourage them from putting money in their account and, on the other hand, discarding its effects on savings (Ky et al., 2018).

\section{Discussion}

\section{Relevance Of Savings Behavior To Developing Economies}

In this review of literature, it has been established that savings behavior is relevant among people in the developing economies. Accumulated savings accumulate capital that can be used in financing business startups, 
health care, and educating the family. These human development indicators are essential in the economic development progress of a country. This is in line with studies by (Sinclair \& Singh, 2015), where savings are the best intervention for poor households in emerging economies. The study highlights that savings improve household wealth and individual wellbeing through increasing an individual's income, investments, and wellbeing. Savings behavior also improves the protection and wellbeing of vulnerable communities in developing economies.

\section{Impact Of Social Influence On Savings Behavior In Developing Countries}

The literature reviewed in this study found that there is a negative impact of social influence on savings behavior in developing economies. It is focused on the fact that most poor people use informal environments (social networks) that are of high-risk, high-cost, and are limited. This, in turn, has contributed to weak savings compared to economies without behavioral frictions. The lack of saving has led to welfare consequences to include variable consumption, low resilience to shocks, and foregone profitable investments (Karlan, Ratan, \& Zinman, 2014). This resonates with the findings of Ky, Rugemintwari, \& Sauviat (2018), who noted that developing economies are surrounded with unforeseen events such as health degradation, the death of a family member, overwhelms and scares the few savings that would have accrued, thereby hindering economic activity and growth.

\section{Conclusion}

Individual savings behavior, which is inherently tricky, allows one to possess essential skills along with a positive impact on their social ties (Jamal et al., 2015; Khatun, 2018). The social context of individuals in developing countries contributes significantly to savings behavior. However, the same social context impairs the financial behavior of individuals in developing countries, given the high level of responsibilities that range from burial contributions, wedding ceremonies, among others. Financial education is one of the main tools for enhancing people's saving attitudes. As a result, providing financial education and training to individuals could mitigate the effects of bad financial habits and attitudes that could be acquired from others. In other words, training may help all kinds of people, including those who might otherwise be considered to be more financially competent and less in need of that kind of training. However, they may be more susceptible to social influence. Using financial education - financial literacy training - individuals should get acquainted with the concept of savings and can learn how to manage money in and outflows. To ensure appropriate savings behavior, an integrated approach involving other factors, such as instilling self-control among individuals, is required.

\section{Theoretical Implication}

This study demonstrates that Life-cycle theory can guide people to manage to spend. Individuals are encouraged to borrow during low-income times and save during cycles of high income. This implies that future studies on savings behavior should utilize life cycle theory.

\section{Practical Implication}

In practice, the Life cycle theory should be utilized where people are encouraged to save in various forms, which include assets such as land, animals, among others. Given the informal nature of businesses in the developing world and the various sectors of engagement, such as animal husbandry, poultry, and crop farming. Saving is necessary at all stages of one's life span through more effort should be made during one's young productive ages. This is more vivid in developing countries where, given the forces of social influence that cause uncalled for expenditure, the majority of active youth have to save part of their income during their productive years. Individual accumulated savings should be encouraged since it contributes to capital accumulation that supports a country's economic growth 


\section{Managerial Implication}

Managers should sensitize their workers on the advantage of the saving. Where possible, managers should deduct an agreeable percentage on their earnings on the source to be saved regularly. This accumulated saving can be useful at retirement

\section{Areas for Future Research}

Future studies should explore the other determinants of Savings Behavior other than Social Influence discussed in this study. An empirical study on the effect of Social Influence on Savings Behavior is recommended. Lastly, a comparative study in various contexts on the effect of Social Influence and Savings Behavior can be undertaken.

Funding: This research received funding from both Makerere University Business School and Moi University.

Acknowledgments: I would like to thank both Makerere University Business School and Moi University for the chance to study at Moi University. To all, my supervisors Dr. Naomi Koskei and Dr. Ernest Saina, express my heartfelt gratitude for their tireless efforts to go through my research and guide me accordingly.

Conflicts of Interest: The authors did not have any conflicts of interest.

\section{References}

Alwi, S., Amir Hashim, I. Z., \& Ali, M. S. (2015). Factors affecting savings habits within millennials in Malaysia: Case study on students of Taylor's University. Paper presented at The Fourth Asia-Pacific Conference on Global Business, Economics, Finance and Social Sciences.

Ando, A., \& Modigliani, F. (1963). The" life cycle" hypothesis of saving: Aggregate implications and tests. The American economic review, 53(1), 55-84.

Ariffin, M. R., Sulong, Z., \& Abdullah, A. (2017). Students' Perception towards Financial Literacy and Saving Behavior. World Applied Sciences Journal, 35(10), 2194-2201.

Asare, E., Segarra, E., Gertrude, N., \& Asiseh, F. (2018). Explaining the Saving Behavior of Households' in Ethiopia, Africa. Applied Economics and Finance, 5(2), 143-151.

Awais, M., Laber, M. F., Rasheed, N., \& Khursheed, A. (2016). Impact of Financial Literacy and Investment Experience on Risk Tolerance and Investment Decisions: Empirical Evidence from Pakistan. International Journal of Economics and Financial Issues, 6(1), 73-79.

Bonga-Bonga, L., \& Guma, N. (2017). The relationship between savings and economic growth at the disaggregated level. Economia Internazionale, 70(1), 1-24.

Bowen, C. F. (2002). Financial knowledge of teens and their parents. Financial counseling and planning, 13(2), 93102.

Browning, M., \& Lusardi, A. (1996). Household saving: Micro theories and micro facts. Journal of Economic Literature, 34(4), 1797-1855.

Bucciol, A., \& Veronesi, M. (2014). Teaching children to save: What is the best strategy for lifetime savings? . Journal of Economic Psychology(45), 1-17.

Chowa, G. A., Masa, R. D., \& Sherraden, M. (2012). Wealth effects of an asset-building intervention among rural households in Sub-Saharan Africa. Journal of the Society for Social Work and Research, 3(329-345).

Collins, J., \& Hussey, R. (2009). Business Research: A practical guide for undergraduate and postgraduate students (3 ed.). New York: Palgrave Macmillan.

Dangol, J., \& Maharjan, S. (2018). Parental and Peer Influence on the Saving Behavior of the Youth. Nepal: Tribhuvan University.

De Noose, C. (2011). Best Practices in Microsaving for Successfully and Sustainably Reaching the Poor. http://www.savings-banks.com 
Deaton, A. (2005). Measuring poverty in a growing world (or measuring growth in a poor world). Review of Economics and Statistics, 87(1), 1-19.

Demirguc-Kunt, A., Klapper, L., Singer, D., \& Van Oudheusden, P. (2015). The Global Findex Database 2014: Measuring Financial Inclusion around the World. Retrieved from Washington, DC:

Duflo, E., \& Saez, E. (2002). Participation and investment decisions in a retirement plan: The influence of colleagues' choices. Journal of Public Economics, 85(1), 121-148.

Dupas, P., \& Robinson, J. (2013). Savings constraints and microenterprise development: Evidence from a field experiment in Kenya. American Economic Journal: Applied Economics, 5(1), 163-192.

Elias, S., \& Worku, A. (2015). Causal relationship between gross domestic saving and economic growth in east Africa: evidence from Ethiopia, Uganda and Kenya. Journal of Agriculture and Social Research (JASR), 15(2), 31-39.

Erskine, M., Kier, C., Leung, A., \& Sproule, R. (2006). Peer crowds, work experience, and financial saving behavior of young Canadians. Journal of Economic Psychology, 27(2), 262-284.

Findley, T. S., \& Caliendo, F. N. (2015). Time Inconsistency and Retirement Choice Economics Letters(129), 48.

Firmansyah, D. (2014). The Influence of Family Backgrounds toward Student Saving Behavior: A Survey of College Students in Jabodetabek. International Joumal of Scientific and Research Publication, 4(1), 1-6.

Franzoi, S. L. (2006). Social psychology (Vol. 4th ed.). New York:: McGraw-Hill.

Geda, A., \& Shimeless, A. (2006). Openness, inequality and poverty in Africa. Retrieved from

Gerhard, P., Gladstone, J. J., \& Hoffmann, A. O. (2018). Psychological characteristics and household savings behavior: The importance of accounting for latent heterogeneity. Journal of Economic Bebavior \& Organization, 148, 66-82.

Gourinchas, P. O., \& Parker, J. A. (2002). Consumption over the life cycle Econometrica, 70(1), 47-89.

Herawati, N. T., Candiasa, I. M., Yadnyana, I. K., \& Suharsono, N. (2018). Factors That Influence Financial Behavior among Accounting Students in Bali. International Journal of Business Administration, 9(3), 30-38.

Hira, T. K. (1997). Financial attitudes, beliefs and behaviors: Differences by age. Journal of Consumer Studies and Home Economics, 21, 271-290.

Homan, A. M. (2016). The influence of parental financial teaching on saving and borrowing behavior. (Masters), University of University of Groningen.

Jamal, A. A. A., Ramlan, W. K., Karim, M. A., \& Osman, Z. (2015). The effects of social influence and financial literacy on savings behavior: A study on students of higher learning institutions in Kota Kinabalu, Sabah. International Journal of Business and Social Science, 6(11), 110-119.

Jappelli, T., \& Modigliani, F. (1998). The age-saving profile and the lifecycle bypothesis. CSEF working paper, (No. 9). Joshi, A., Pradhan, S., \& Bist, J. P. (2019). Savings, investment, and growth in Nepal: an empirical analysis. Financial Innovation, 5(1).

Kaberuka, W., \& Namubiru, R. (2014). The effect of remittances on gross domestic savings in Uganda (19992011). International Journal of Business Management and Administration, 3(2), 29-39.

Karlan, D., Ratan, A. L., \& Zinman, J. (2014). Savings by and for the Poor: A Research Review and Agenda. Review of Income and Wealth, 60(1), 36-78.

Kast, F., Meier, S., \& Pomeranz, D. (2018). Saving more in groups: Field experimental evidence from Chile. Journal of Development Economics, 133, 275-294.

Keynes, J. M. (1936). The general theory of interest, employment and money.

Khatun, M. (2018). Effect of Financial Literacy and Parental Socialization on Students Savings Behavior of Bangladesh. International Journal of Scientific and Research Publications, 8(12), 296-305.

Kudaisi, B. V. (2013). Savings and its determinants in West Africa countries. Journal of Economics and Sustainable Development, 4(18), 107-119. 
Ky, S., Rugemintwari, C., \& Sauviat, A. (2018). Does mobile money affect saving behaviour? Evidence from a developing country. Journal of African Economies, 27(3), 285-320.

Laible, D. J., Carlo, G., \& Roesch, S. C. (2004). Pathways to self-esteem in late adolescence: The role of parent and peer attachment, empathy, and social behaviors. Journal of adolescence, 27(6), 703-716.

Lyons, A. C. (2007). Credit practices and financial education needs of Midwest college students. Networks Financial Institute Working Paper, (2007-WP).

Mahdzan, N. S., \& Tabiani, S. (2013). The impact of financial literacy on individual saving: An exploratory study in the Malaysian context. Transformations in Business \& Economics, 12(1), 41-55.

Mangleburg, T. F., Doney, P. M., \& Bristol, T. (2004). Shopping with friends and teens' susceptibility to peer influence. Journal of retailing, 80(2), 101-116.

Modigliani, F. (1970). The life cycle hypothesis of saving and inter-country differences in the saving ratio. Induction, growth and trade, 197-225.

Modigliani, F., \& Brumberg, R. (1954). Utility analysis and the consumption function: An interpretation of cross-section data. Post-keynesian economics, 1, 338-436.

Njenga, G., Onuonga, S. M., \& Sichei, M. M. (2018). Institutions' effect on households' savings in Kenya: A ranked ordered multinomial/ conditional probit model approach. Retrieved from

Norvilitis, J. M., \& MacLean, M. G. (2010). The role of parents in college students' financial behaviors and attitudes Journal of Economic Psychology, 31(1), 55-63.

Otto, A. (2013). Saving in childhood and adolescence: Insights from developmental psychology. Economics of Education Review, 33, 8-18.

Prawitz, A., Garman, E. T., Sorhaindo, B., O'Neill, B., Kim, J., \& Drentea, P. (2006). InCharge financial distress/financial wellbeing scale: Development, administration, and score interpretation. Journal of Financial Counseling and Planning, 17(1).

Romer, P. M. (1986). Increasing returns and long-run growth. Journal of Political Economy, 94(5), 1002-1037.

Sabri, M. F., \& MacDonald, M. (2010). Savings behavior and financial problems among college students: The role of financial literacy in Malaysia. Cross-Cultural Communication, 6(3), 103-110.

Sam, Y., Geetha, C., \& Mohidin, R. (2012). What were the factors that influence financial management behavior of undergraduates? . International Journal of Business Trends and Technology, 2(1), 2249-0183.

Shim, S., Barber, B. L., Card, N. A., Xiao, J. J., \& Serido, J. (2010). Financial socialization of first-year college students: The roles of parents, work, and education. Journal of Youth and Adolescence, 39(12), 1457-1470.

Sinclair, R., \& Singh, N. (2015). Savings Groups and their Role in Child Wellbeing: A Primer for Donors.

Solow, R. M. (1956). A contribution to the theory of economic growth. The quarterly journal of economics, 70(1), 65-94.

Supanantaroek, S., Lensink, R., \& Hansen, N. (2017). The impact of social and financial education on savings attitudes and behavior among primary school children in Uganda. Evaluation review, 41(6), 511-541.

Tharanika, K., \& Andrew, A. (2017). Factors Influencing On Saving Behavior Among University Students. $4(14), 861-871$.

Turan, G., \& Gjergji, O. (2014). What is the impact of savings on growth? The case of a small open economy (Albania). Mediterranean Journal of Social Sciences, 5(13).

Webley, P., \& Nyhus, E. K. (2006). Parents' influence on children's future orientation and saving. Journal of Economic Psychology, 27(1), 140-164.

World Bank. (2017). End Extreme Poverty: Boost Shared Prosperity. Retrieved from Washington, D.C.: http://documents.worldbank.org/curated/en/143021506909711004/World-Bank-Annual-Report$\underline{2017}$

Zaihan, N. D. (2016). Determinants of saving behavior among generation Y students in Universiti Utara Malaysia. (PhD), Universiti Utara Malaysia. 